\title{
The oxidative coupling of methane and the oxidative dehydrogenation of ethane over a niobium promoted lithium doped magnesium oxide catalyst
}

\author{
H.M. Swaan', Y. Li', K. Seshan', J.G. Van Ommen' and J.R.H. Ross \\ 1)Faculty of Chemical Technology, University of Twente, P.O. Box 217, 7500 AE Enschede, \\ The Netherlands. \\ 2)Tianjin University, Department of Chemical Engineering, Tianjin 300072, P. R. China. \\ 3) University of Limerick, Department of Industrial Chemistry and Life Sciences, Limerick, Ireland.
}

\begin{abstract}
The promoting effect of niobium in a Li/MgO catalyst for the oxidative coupling of methane $(O C M)$ and for the oxidative dehydrogenation of ethane (ODHE) has been studied in some detail. It has been found that a $\mathrm{Li} / \mathrm{Nb} / \mathrm{MgO}$ catalyst with $16 \mathrm{wt} \%$ niobium showed the highest activity for the $\mathrm{C}_{2}$ production in the $\mathrm{OCM}$ reaction; the activity at $600^{\circ} \mathrm{C}$ was ten times that of the $\mathrm{LI} / \mathrm{MgO}$ catalyst at the same temperature. The $\mathrm{Li} / \mathrm{Nb} / \mathrm{MgO}$ catalyst was also slightly more active for the ODHE reaction than was the $\mathrm{Li} / \mathrm{MgO}$ catalyst. However, the $\mathrm{Li} / \mathrm{Nb} / \mathrm{MgO}$ catalyst produced considerably more carbon dioxide in the both reactions. Structural investigation of the catalyst showed that the addition of niobium to the $\mathrm{Li} / \mathrm{MgO}$ catalyst increased the surface area and gave an increase in the lithium content of the calcined catalysts. Two niobium phases, $\mathrm{LiNbO}_{3}$ and $\mathrm{Li}_{3} \mathrm{NbO}_{4}$, were formed; it is shown that the first of these probably causes the increased activity. Ageing experiments showed that the activity of the catalyst was lost if the catalyst was used above $720^{\circ} \mathrm{C}$, the melting point of the lithium carbonate phase. The catalyst showed a decrease of surface area after ageing and a sharp decrease of the amount of the two niobium phases. The addition of carbon dioxide to the feed could not prevent the deactivation of the $\mathrm{Li} / \mathrm{Nb} / \mathrm{MgO}$ catalyst.
\end{abstract}

\section{INTRODUCTION}

Lithium doped magnesium oxide $(\mathrm{Li} / \mathrm{MgO})$ is well established as a catalyst for the oxidative coupling of methane (OCM) [1]. It has also been shown [2] that $\mathrm{LI} / \mathrm{MgO}$ is a good catalyst for the oxidative dehydrogenation of ethane (ODHE). It has recently been shown in this laboratory that the performance of this catalyst can be improved by the addition of dopants [3]; for example, the addition of tin oxide and cobalt oxide increased the activity of the $\mathrm{Li} / \mathrm{MgO}$ catalyst. However, their presence decreased the selectivity to $\mathrm{C}_{2}$ products. The $\mathrm{Li} / \mathrm{Sn} / \mathrm{MgO}$ catalyst has the advantage that the operating temperature can be lowered relative to the undoped catalyst, while reaching similar methane conversions. It has also been shown in our laboratory that the $\mathrm{LI} / \mathrm{MgO}$ catalyst deactivates at temperatures higher than $750^{\circ} \mathrm{C}$, because of loss of lithium. A $\mathrm{Li} / \mathrm{Sn} / \mathrm{MgO}$ catalyst however, operating at lower temperatures, exhibits a lifetime of more than $500 \mathrm{hrs}$ [3].

A recent investigation in our laboratory has shown that niobium oxide is a selective catalyst for the oxidative dehydrogenation of propane [4]. Niobium oxide has also been added as a promotor to a molybdenum - vanadium oxide catalyst used for the ODHE reaction [5,6] and to a manganeselanthanide oxide catalyst used for the production of ethylene by means of steam cracking of butane [7]. It has also been shown that niobium oxide is a suitable promoter for the $\mathrm{Li} / \mathrm{MgO}$ catalyst in the OCM reaction [8]. More recently, it was shown [9] that various promoted Li/MgO catalysts exhibit simllar behaviour when used for the $O C M$ and $O D H E$ reactions. However, the reason for the promoting role of niobium in the $\mathrm{LI} / \mathrm{Nb} / \mathrm{MgO}$ catalyst is not known.

This paper thus describes research in which several niobium promoted catalysts with different 
amounts of niobium were prepared using a number of different methods of preparation; these catalysts were tested for the OCM and ODHE reactions. The textural properties of these catalysts were investigated in order to correlate these characteristics with their catalytic performances.

\section{EXPERIMENTAL}

Preparation of the catalysts The catalysts, shown in Table 1 , were made by various methods. The standard methods of wet mixing and dry mixing mentioned in the table are described by Korf [3], In the case of the wet mixing, the niobium precursor $(0.2 \mathrm{mmol} / \mathrm{g}$ cat) was added during the impregnation stage; the niobium oxide was milled and added as a slurry to the solution of lithium hydroxide. In the case of dry mixing, the niobium oxide was added after the drying stage. The other preparation methods used are discussed in the text. Table 1 shows the composition of several niobium promoted catalyst of Series 1 . The catalysts contained relatively a high quantity of lithium ( 5.3 to $6.3 \mathrm{wt} \%$ ) after calcination compared with the $\mathrm{Li} / \mathrm{MgO}$ catalyst, although the same amount of lithium was used during preparation. Different nloblum concentrations were used, varying from 11.5 to $20.8 \mathrm{wt} \%$. In the case of the catalyst $\mathrm{Li} / \mathrm{Nb} / \mathrm{MgO}$ (1), the niobium oxide was added as niobium oxide to a solution of lithium hydroxide. In the case of the catalyst (2), the niobium was added to the $\mathrm{Li} / \mathrm{MgO}$ catalyst after the drying step, but before the calcination step. In the case of catalysts $\mathrm{Li} / \mathrm{Nb} / \mathrm{Mg}(3)$ and (4), the niobium was added as a magnesium niobate compound to a lithium hydroxide solution.

Catalyst Characterisation. The surface area of the catalyst was determined by means of a Micromeritics ASAP 2400 system, using nitrogen adsorption at $78 \mathrm{~K}$. The melting behaviour of the phases was analyzed by means of a PL Thermal Sciences (DSC-TG 1500); a differential scanning calorimeter /thermogravimetric analysis instrument. The crystal phases present in the catalyst were determined by means of a Philips PW 1710 diffractometer using Cu-K $\mathrm{K}_{\alpha}$ radiation.

Catalytic testing. All the catalytic testing experiments were done in a conventional co-feed reactant flow system with on-line GC analysis. In the case of the OCM reaction, a fixed bed of catalyst with a loading of $375 \mathrm{mg}$ was retained in a quartz tubular reactor of $5 \mathrm{~mm}$ internal diameter. The temperature of the catalyst was measured with a thermocouple in a thin quartz tube, the junction being located in the middle of the catalyst bed. A standard gas feed consisting of $76 \mathrm{kPa} \mathrm{CH}_{4}, 7 \mathrm{kPa} \mathrm{O}$ and $18 \mathrm{kPa}$ He was used, with a flow rate of $100 \mathrm{ml} / \mathrm{min}$. Experiments were also performed with a gas ratio of $\mathrm{CH}_{4} / \mathrm{O}_{2}=5$ and with

Table 1. Catalyst composition of the fresh $\mathrm{Li} / \mathrm{Nb} / \mathrm{MgO}$ catalysts (Series 1) and the method of preparation used.

\begin{tabular}{lllll}
\hline & \multicolumn{2}{l}{} & \multicolumn{2}{l}{ Fresh catalyst } \\
\hline Catalyst & $\begin{array}{r}\text { Preparation } \\
\text { Method }\end{array}$ & & \multicolumn{2}{l}{ Chem.Comp./wt\% } \\
\cline { 4 - 5 } & wet mixing & $\mathrm{Mg}(\mathrm{OH})_{2}$ & $\mathrm{Li}$ & $\mathrm{Nb}$ \\
\hline $\mathrm{Li} / \mathrm{MgO}$ & wecursors & & \\
$\mathrm{Li} / \mathrm{Nb} / \mathrm{MgO}(1)$ & wet mixing & $\mathrm{LiNbO}_{3}, \mathrm{Mg}(\mathrm{OH})_{2}$ & 5.1 & 17.4 \\
$\mathrm{Li} / \mathrm{Nb} / \mathrm{MgO}(2)$ & dry mixing & $\mathrm{Nb}_{2} \mathrm{O}_{5}, \mathrm{Li}_{2} \mathrm{CO}_{3}, \mathrm{Mg}(\mathrm{OH})_{2}$ & 5.5 & 18.4 \\
$\mathrm{Li} / \mathrm{Nb} / \mathrm{MgO}(3)$ & wet mixing & $\mathrm{MgNb}_{2} \mathrm{O}_{6}, \mathrm{Mg}(\mathrm{OH})_{2}$ & 6.3 & 11.5 \\
$\mathrm{Li} / \mathrm{Nb} / \mathrm{MgO}(4)$ & wet mixing & $\mathrm{Mg}-\mathrm{Nb}-\mathrm{O}$ & 5.3 & 20.8
\end{tabular}

1) The amount of $\mathrm{Mg}, \mathrm{C}$ and $\mathrm{O}$ were not measured.

2) $\mathrm{LiOH}$ in an aqueous solution was used unless stated otherwise. 
$\mathrm{CO}_{2}$ also present in the feed; the flow rate being kept constant in all cases. Some experiments were also carried out without He diluent. The reactor temperature was normally programmed in 11 steps, starting at $575{ }^{\circ} \mathrm{C}$, and ending at $825^{\circ} \mathrm{C}$; during the $1.4 \mathrm{hrs}$ period of each step a series of gas samples was taken by the sampling loop. The products were analyzed by means of a Varian 3700 GC equipped with a carbosieve SII column. To study the deactivation of the catalysts, the same programme was sometimes repeated three times in a cyclic mode; the reactor was cooled to room temperature between the cycles. The ageing experiments were all performed using $\mathrm{CH}_{4} / \mathrm{O}_{2}=5$, but sometimes with additional $\mathrm{CO}_{2}$. The activity of the catalyst for the ODHE reaction was tested in the manner described previously [9]. The feed consisted of 12 vol\% ethane (.99 vol\%, UCAR), 6 vol \% oxygen ( $>99.5 \%$, Hoekloos) and 82 vol \% helium $(99.9 \%$, UCAR). An amount of $6.2 \mathrm{~g}$. catalyst was used (particle size $0.3-0.6 \mathrm{~mm})$. The reactor temperature was increased in steps from $520^{\circ} \mathrm{C}$ to $640^{\circ} \mathrm{C}$.

\section{RESULTS AND DISCUSSION}

Influence of the preparation method on the behaviour for the OCM reaction.

Figure 1 shows the $C_{2}$ yield in the OCM reaction versus the reactor temperature for these $\mathrm{Li} / \mathrm{Nb} / \mathrm{MgO}$ catalysts; the performance of the unpromoted $\mathrm{Li} / \mathrm{MgO}$ catalyst is also given. It is seen that, with the niobium promoted catalysts, the temperature could be reduced by $40{ }^{\circ} \mathrm{C}$ to reach similar $C_{2}$ yields as those given by the $\mathrm{Li} / \mathrm{MgO}$ catalyst. The catalysts $\mathrm{Li} / \mathrm{Nb} / \mathrm{MgO}$ (1) (17.4 wt\% Nb), in which lithium was added as $\mathrm{LiNbO}_{3}$, and $\mathrm{Li} / \mathrm{Nb} / \mathrm{MgO}(2)$, in which dry mixing was used, showed the highest activities. A maximum yield of $12 \%$ (corresponding to total oxygen conversion) was achieved at a temperature as low as $730^{\circ} \mathrm{C}$. The $\mathrm{Li} / \mathrm{Nb} / \mathrm{MgO}$ (3) catalyst as well as $\mathrm{Li} / \mathrm{Nb} / \mathrm{MgO}$ (4) showed a slightly lower activity. The results indicated that the most active catalyst was formed when lithium was added together with the niobium. The dry mixing procedure gave a catalyst as good as that with the wet mixing procedure.

Table 2 . Catalyst composition of the fresh $\mathrm{Li} / \mathrm{Nb} / \mathrm{MgO}$ catalysts (Series 2) all prepared by means of wet mixing.

\begin{tabular}{|c|c|c|c|c|c|c|}
\hline \multirow{3}{*}{ Catalyst } & \multicolumn{3}{|c|}{ Fresh catalyst } & \multicolumn{3}{|c|}{ Used Catalyst } \\
\hline & \multicolumn{2}{|c|}{$\begin{array}{l}\text { Composition ") } \\
\text { /wt\% }\end{array}$} & \multirow[t]{2}{*}{ S.A. $/ \mathrm{m}^{2} \cdot \mathrm{g}^{-1}$} & \multicolumn{2}{|c|}{ Composition /wt \% } & \multirow[t]{2}{*}{ S.A. $/ \mathrm{m}^{2} \cdot \mathrm{g}^{-1}$} \\
\hline & $\mathrm{Li}$ & $\mathrm{Nb}$ & & $\mathrm{LI}$ & $\mathrm{Nb}$ & \\
\hline $\mathrm{Li} / \mathrm{Nb} / \mathrm{MgO}$ (5) & 6.7 & 10 & 4.7 & 6.4 & 9.5 & - \\
\hline LI/Nb/MgO (6) & 6.1 & 15.5 & 6.7 & 5.0 & 15.5 & 3.7 \\
\hline $\mathrm{Li} / \mathrm{Nb} / \mathrm{MgO}$ (7) & 6.9 & 21.8 & 6.1 & 5.2 & 21.9 & 0.9 \\
\hline $\mathrm{Li} / \mathrm{MgO}$ & 3 & . & 1.2 & & & \\
\hline
\end{tabular}

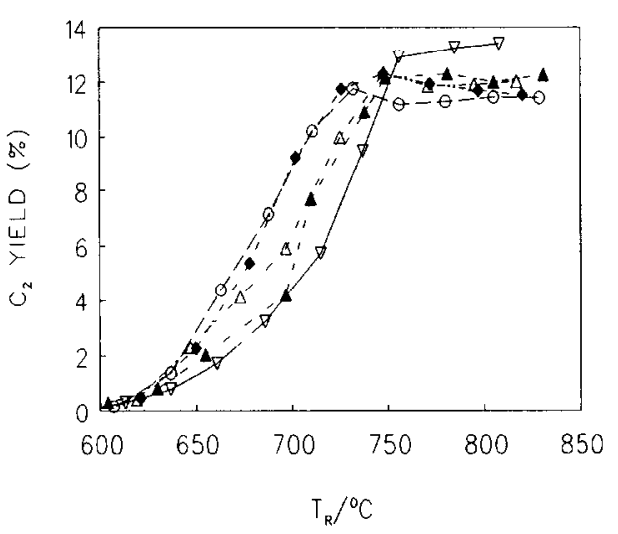

Figure 1 The $C_{2}$ Yield as function of the reactor

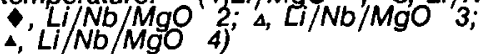

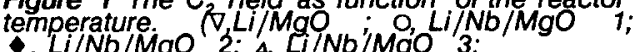




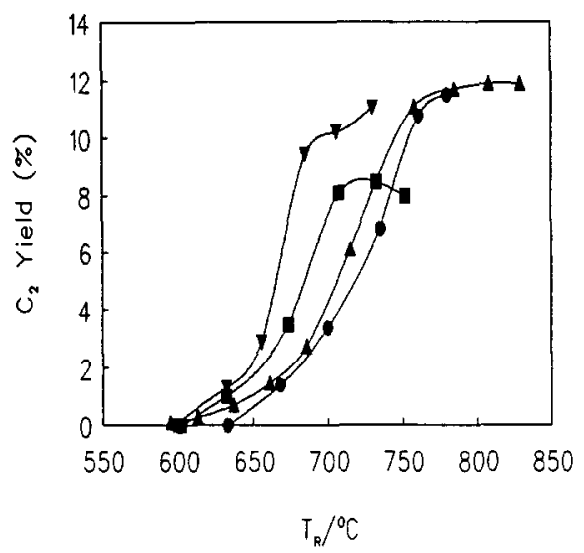

Figure 2 C Yield as a function of the reaction têmperature for Li/Nb/MgO catalysts (A, 0 wt\%; $\bullet, 11.5$ wt\% $\checkmark, 15.5 w t \% ;, 21.8 w t \% \mathrm{Nb})$.

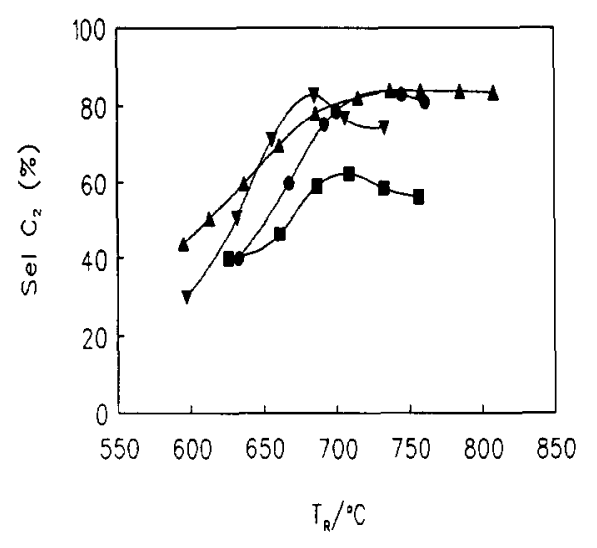

Figure 3 Selectivity to $C_{2}$ products as a function of temperature ${ }^{2}$ for Li/nb/MgO 15.5 WT\%; - 21.8 WT\%' $N b$ ).

\section{Influence of the Niobium Concentration}

The influence of the niobium concentration was examined by preparing three additional catalysts, by wet mixing, with different amounts of niobium, varying from 10 to 22 wt\% (see Table 2.). The lithium concentrations of these catalysts varied between 6 and $7 \mathrm{wt} \%$. The surface areas measured for the promoted catalysts were significantly higher (up to $6.7 \mathrm{~m}^{2} / \mathrm{g}$ ) than that for the $\mathrm{Li} / \mathrm{MgO}$ catalyst. Figure 2 shows the activities as a function of the reactor temperature and Figure 3 shows the corresponding selectivities to ethylene and ethane. It can be seen that the activity of $\mathrm{Li} / \mathrm{Nb} / \mathrm{MgO}(5)$ is slightly lower than that of the $\mathrm{Li} / \mathrm{MgO}$ catalyst. The activity of the catalyst $\mathrm{Li} / \mathrm{Nb} / \mathrm{MgO}$ (6) (with $15.5 \mathrm{wt} \%$ niobium) was remarkably high; a maximum $\mathrm{C}_{2}$ yield of $11 \%$ was obtained at $700{ }^{\circ} \mathrm{C}$.

A catalyst containing $21 \mathrm{wt} \%$ niobium $(\mathrm{Li} / \mathrm{Nb} / \mathrm{MgO}(7))$ also showed a higher activity for the OCM reaction than did the $\mathrm{Li} / \mathrm{MgO}$ catalyst but the $\mathrm{C}_{2}$ yield of the this catalyst was slightly lower than the $\mathrm{C}_{2}$ yield of the catalyst with $15.5 \mathrm{wt} \%$ niobium. The catalyst containing the highest niobium concentration showed a markedly lower selectivity to $C_{2}$ products than did the other samples. These results indicate that the optimum amount of niobium is approximately $16 \mathrm{wt} \%$.

The Oxidative Dehydrogenation of Ethane with the $\mathrm{Li} / \mathrm{Nb} / \mathrm{MgO}$ Catalysts.

Figure 4 shows the yield of ethylene in the ODHE reaction as a function of the reaction temperature, employing the catalyst $\mathrm{Li} / \mathrm{Nb} / \mathrm{MgO}(6)$ and Figure 5 shows the corresponding yield of carbon dioxide as a function of temperature. The catalyst was also tested in a second cycle. The catalyst was aged further for 4 hours at $800^{\circ} \mathrm{C}$ in the feed stream and again tested for the ODHE reaction. These results are compared in Figures 4 and 5 with those for the $\mathrm{Li} / \mathrm{MgO}$ catalyst.

It can be seen that the yield of ethylene is slightly lower with the niobium-promoted catalyst than that with the $\mathrm{Li} / \mathrm{MgO}$ catalyst and that the production of carbon dioxide is significantly higher for the promoted catalyst than for the $\mathrm{Li} / \mathrm{MgO}$. The figures also show that an ageing period at $650^{\circ} \mathrm{C}$, before the second cycle did not influence the performance of the $\mathrm{Li} / \mathrm{Nb} / \mathrm{MgO}$ catalyst. It can be seen that the activity for the ethylene production had remained almost constant (the two curves overlapped). However, the production of carbon dioxide was decreased remarkably after an ageing perlod at $800^{\circ} \mathrm{C}$ and the production of carbon monoxide decreased proportionally. 


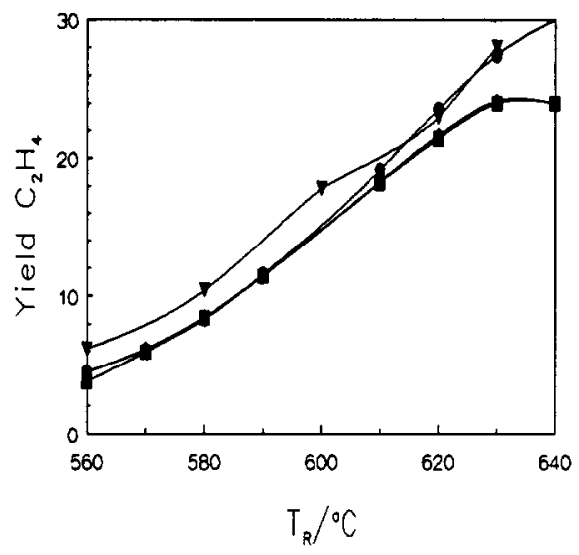

Figure 4. Yield of ethylene, employing the $\mathrm{Li} / \mathrm{MgO}$ catalyst (v) and $\mathrm{Li} / \mathrm{Nb} / \mathrm{MgO} \# 6$ catalyst $\left(\bullet\right.$, fresh; $\bullet 2^{\text {nd }}$ Cycle; $\bullet$, after treatment at $800{ }^{\circ} \mathrm{C}$ ).

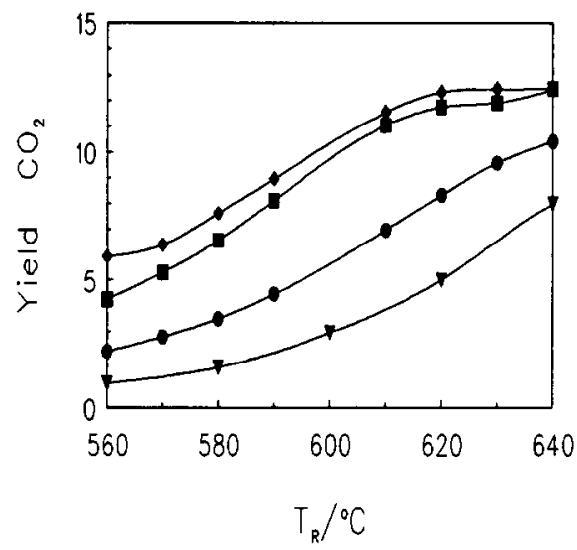

Figure 5 Yield of carbon dioxide, employing the $\mathrm{Li} / \mathrm{MgO}$ catalyst ( $\mathrm{v}$ ) and the $\mathrm{Li} / \mathrm{Nb} / \mathrm{MgO}$ \#6 catalyst ( $\bullet$, fresh; ., $2^{\text {nd }}$ cycle; $\bullet$ after treatment at $800^{\circ} \mathrm{C}$.)

These results indicate that the addition of nioblum to the $\mathrm{Li} / \mathrm{MgO}$ catalyst created very active sites on the surface which are responsible for the formation of the total combustion products. These active sites were apparently lost during the ageing period at $800^{\circ} \mathrm{C}$. However, the catalyst had not lost the activity for the production of ethylene and so this ethylene is probably produced on another type of site.

It has been shown previously [10] that the $\mathrm{Li} / \mathrm{MgO}$ catalyst deactivates at this temperature, due to the loss of lithium. In this experiment the activity of the catalyst for the ethylene production remained constant; the loss of lithium was low because of the low linear velocity of the gases.

\section{Origin of the Promoting Effect of the Niobium Compounds.}

It is of interest to know the reason of the higher activity of the $\mathrm{Li} / \mathrm{Nb} / \mathrm{MgO}$ catalyst compared with the unpromoted $\mathrm{Li} / \mathrm{MgO}$ catalyst. Several possible explanations exist and these will be discussed in turn:

i) Compound formation. The formation of an active niobium containing phase, which can generate the active sites seems most likely. Figure 6 and Figure 7 show the XRD intensities as a function of the diffraction angle $2 \Theta$ of the fresh $\mathrm{Li} / \mathrm{Nb} / \mathrm{MgO}$ catalysts of Series 2. as well as those of one of the aged catalysts. The phases $\mathrm{LiNbO}_{3}$ (trigonal lithium meta-niobate) and $\mathrm{Li}_{3} \mathrm{NbO}_{4}$ (cubic lithium ortho-niobate) can be identified, as well as the $\mathrm{Li}_{2} \mathrm{CO}_{3}$ and $\mathrm{MgO}$ phases, already present in the $\mathrm{Li} / \mathrm{MgO}$ catalyst. The first niobate phase is a n-type conducting material [11]. A set of peaks (at $2 \theta=19.94(4.45 \AA), 2 \theta=$ $23.20(=3.83 \AA)$ and $2 \theta=39.96(2.25 \AA))$, indicated as phase $E$, could not be attributed to any known niobium phase.

In order to quantify the phases present, the ratio between the intensities of the strongest reflection of each phase present in each catalyst and the intensity of the same reflection present in catalyst $\mathrm{Li} / \mathrm{Nb} / \mathrm{MgO}(5)$ were calculated. The values are given in the upper part of Table 3 . The relative intensity results show that the amount of free lithium carbonate decreased, whereas the amounts of the phases $\mathrm{LiNbO}_{3}$ and $\mathrm{Ll}_{3} \mathrm{NbO}_{4}$ increased with the niobium concentration. After use, the amount of the unknown phase $E$ in the catalyst had increased and the amount of each of the niobium phases had decreased. Catalyst $\mathrm{Li} / \mathrm{Nb} / \mathrm{MgO}(6)$ was the most active sample examined and catalyst (7) was only slightly less active, even though the latter catalyst contained a larger portion of the niobate phases. The 


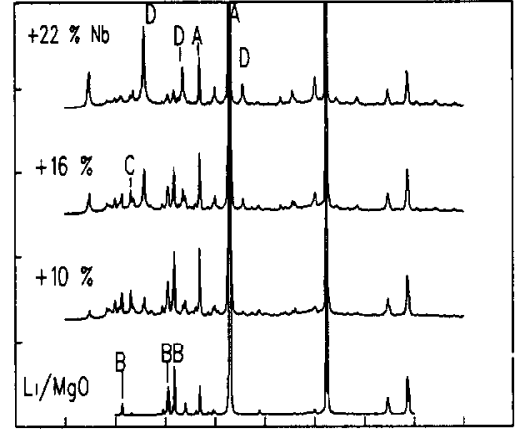

$\begin{array}{lllllllllll}0 & 10 & 20 & 30 & 40 & 50 & 60 & 70 & 80 & 90 & 100\end{array}$

\section{Theta}

Figure 6 XRD pattern of fresh $\mathrm{Li} / \mathrm{Nb} / \mathrm{MgO}$ materials.

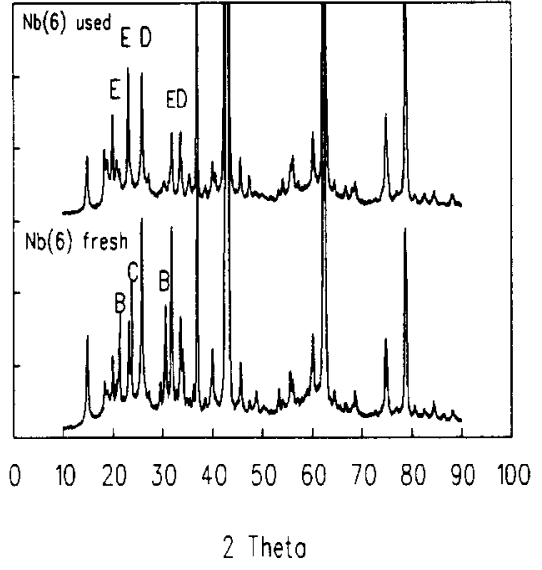

Figure 7 XRD Pattern of Fresh and Used $\mathrm{Li} / \mathrm{Nb} / \mathrm{MgO}$ catalyst with $16 \mathrm{wt} \% \mathrm{Nb}$

meta-niobate phase is probably the cause of the increased activity. Our group has shown previously that the addition of an n-type conducting compound $\left(\mathrm{e.g} . \mathrm{SnO}_{2}\right)$ to a $\mathrm{Li} / \mathrm{MgO}$ catalyst increased its activity, probably because this promoter enhances the interaction of oxygen with the catalyst surface. Kinetic experiments of the OCM reaction over a $\mathrm{Li} / \mathrm{Sn} / \mathrm{MgO}$ catalyst showed an improved oxygen adsorption [8]. It is likely that the same phenomenon had taken place upon addition of the niobium oxide. The lowest line of Table 3 gives the activity for the $\mathrm{OCM}$ reaction at $630^{\circ} \mathrm{C}$ and the results seem to indicate that the activity is probably not proportional to the amount of this niobate phase $\left(\mathrm{LiNbO}_{3}\right)$.

It is unlikely that the increased activity of the catalyst is to be attributed to the presence of the ortho-niobate phase $\left(\mathrm{Li}_{3} \mathrm{NbO}_{4}\right)$. There is twice as much of the phase $\mathrm{Li}_{3} \mathrm{NbO}_{4}$ present in $\mathrm{Li} / \mathrm{Nb} / \mathrm{MgO}(7)$ than in $\mathrm{Li} / \mathrm{Nb} / \mathrm{MgO}$ (6). However the activity of the catalyst $\mathrm{Li} / \mathrm{Nb} / \mathrm{MgO}(7)$ is not twice that of catalyst $\mathrm{Li} / \mathrm{Nb} / \mathrm{MgO}(6)$. The amount of the unknown phase $\mathrm{E}$ had increased after deactivation of the catalyst and is also unlikely to be responsible for the OCM reaction.

Table 3 XRD refiections of phases formed in the $\mathrm{Li} / \mathrm{Nb} / \mathrm{MgO}$ catalyst and activity of the at $630^{\circ} \mathrm{C}$

\begin{tabular}{|c|c|c|c|c|c|c|c|}
\hline \multirow[t]{2}{*}{$2 \theta$} & \multirow{2}{*}{$d_{(A)}$} & \multirow[t]{2}{*}{ Phase } & \multicolumn{5}{|c|}{ Relative Intensities of Reflections } \\
\hline & & & $\begin{array}{l}\mathrm{Li} / \mathrm{MgO} \\
\text { fresh }\end{array}$ & $\begin{array}{l}\mathrm{Li} / \mathrm{Nb} / \mathrm{MgO \# 5} \\
(11.5 \text { wt\% Nb) } \\
\text { tresh }\end{array}$ & $\begin{array}{l}\mathrm{Nb} \# 6 \\
(15.5 \text { wt\%) } \\
\text { fresh }\end{array}$ & $\begin{array}{l}\mathrm{Nb} \# 7 \\
(21.8 \text { wt\%) } \\
\text { tresh }\end{array}$ & $\begin{array}{l}\mathrm{Nb \#} 6 \\
\text { used }\end{array}$ \\
\hline 19.94 & 4.45 & $E$ & $(-)$ & 1 & 0.94 & 0.86 & 1.06 \\
\hline 21.35 & 4.16 & $\bar{B}$ & 1.09 & 1 & 0.65 & 0.31 & 0.17 \\
\hline 23.70 & 3.75 & C & - & 1 & 2.14 & 2.57 & 1.15 \\
\hline 25.80 & 3.44 & D & - & 1 & 2.30 & 4.30 & 1.52 \\
\hline 36.95 & 2.42 & A & 0.98 & 1 & 0.84 & 0.70 & 0.75 \\
\hline \multicolumn{3}{|c|}{ Activity: $r^{1}$} & 4.0 & 2.2 & 32 & 13 & 16 \\
\hline
\end{tabular}

$\mathrm{A}=\mathrm{MgO}$ (Cubic); $\mathrm{B}=\mathrm{Li}_{2} \mathrm{CO}_{3}$ (Monoclinic); $\mathrm{C}=\mathrm{LiNbO}_{3}$ (Trigonal); $\mathrm{D}=\mathrm{Li}_{3} \mathrm{NbO}_{4}$ (Cubic); $\mathrm{E}=$ (Nb)

1) rate $/ 10^{-7} \mathrm{~mol}\left(\mathrm{CH}_{4}\right) \cdot(\mathrm{g}(\mathrm{cat}) \cdot \mathrm{s})^{-1}$. 


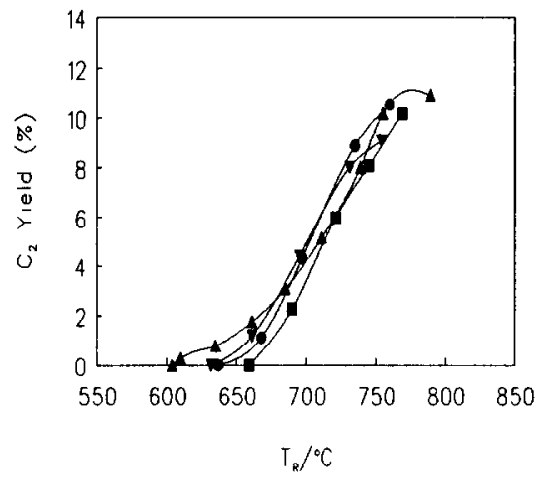

Figure $8 \mathrm{C}_{2}$ Yield as a function of the reactor temperature, during a second cycle of $\mathrm{Li} / \mathrm{Nb} / \mathrm{MgO}$ catalyst (first test and symbols: see Figure 2.).

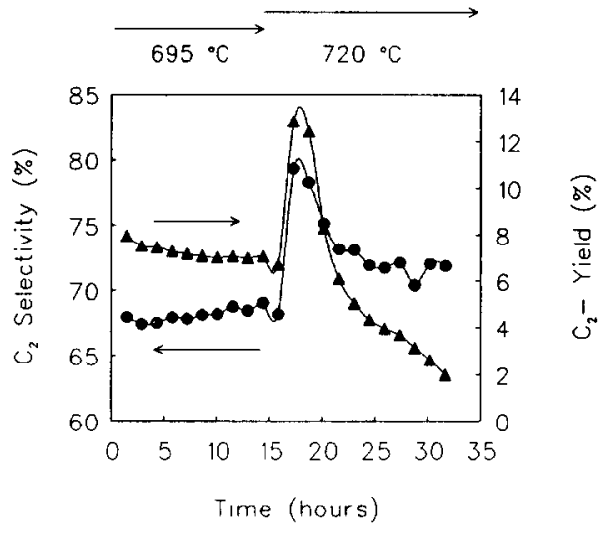

Figure 9 Influence of temperature upon deactivation of a $L i / \mathrm{Nb} / \mathrm{MgO}$ \#6 catalyst. $\left(\bullet, C_{2}\right.$ Selectivity: $\triangle, C_{2}$ Yield)

ii) Increase of surface area. The fresh $\mathrm{Li} / \mathrm{Nb} / \mathrm{MgO}$ catalyst possesses a higher surface area than $\mathrm{Li} / \mathrm{MgO}$. Table 3 shows that the catalyst containing $15.5 \mathrm{wt} \% \mathrm{Nb}$ had an initial surface area of $6.7 \mathrm{~m}^{2} / \mathrm{g}$. After use, the surface area had decreased to $3.7 \mathrm{~m}^{2} / \mathrm{g}$, a value still higher than that for the fresh $\mathrm{Li} / \mathrm{MgO}$ catalyst. However, this area was similar to the initial surface area of the catalyst $\mathrm{Li} / \mathrm{Nb} / \mathrm{MgO}(5)$, which had a similar activity to the $\mathrm{Li} / \mathrm{MgO}$ catalyst. It is not possible to reject or accept this possibility on basis of these results.

iii) Change in lithium content. The XRD spectra show that the amount of lithium carbonate had decreased in the niobium-promoted catalysts. It has been shown by Korf et al. [9] that 3 wt\% lithium in the $\mathrm{Li} / \mathrm{MgO}$ catalyst gives an optimum catalyst, a catalyst with $2 \mathrm{wt} \%$ of lithium showed a slightly higher activity but rapid deactivation. This means that, in principle, a decrease in the content of lithium carbonate can cause an increase in activity. The results of the ODHE reaction shows that the Li/ $\mathrm{Nb} / \mathrm{MgO}$ catalyst probably has an additional type of active site, which is responsible for the combustion of ethane. It is unlikely therefore that the enhanced activity of the $\mathrm{Li} / \mathrm{Nb} / \mathrm{MgO}$ catalyst can be attributed to a change of the lithium carbonate content.

From the investigation above we can conclude that the formation of the meta-niobate phase is the cause of the increased activity of the $\mathrm{LI} / \mathrm{Nb} / \mathrm{MgO}$ catalyst, possibly in combination with an increase of the surface area of the materials.

\section{Deactivation of the $\mathrm{Li} / \mathrm{Nb} / \mathrm{MgO}$ Catalysts}

It is necessary to know which factors may cause deactivation. Deactivation of $\mathrm{Li} / \mathrm{Nb} / \mathrm{MgO}$ has been observed during the ODHE reaction; the extra activity of the $\mathrm{Li} / \mathrm{Nb} / \mathrm{MgO}(6)$ catalyst was lost when the catalyst was aged at $800^{\circ} \mathrm{C}$. This cause of the deactivation was investigated In more detall with the help of cyclic experiments. In the experiments described below the aged catalysts of Table 2 were tested for deactivation; after the normal OCM screening test the reactor temperature was again increased stepwise. Figure 8 gives the $\mathrm{C}_{2}$ yield as a function of the reactor temperature. The performance of the $\mathrm{Li} / \mathrm{MgO}$ catalyst was equal in both cases; a maximum $\mathrm{C}_{2}$ yield of $11.5 \%$ was reached at $750^{\circ} \mathrm{C}$. It can also be seen that the promoted catalysts still give higher yields than the $\mathrm{Li} / \mathrm{MgO}$ catalyst; however, all the catalysts gave similar $\mathrm{C}_{2}$ yields to those of the $\mathrm{Li} / \mathrm{MgO}$ catalyst at temperatures which were $15^{\circ} \mathrm{C}$ lower whereas the fresh $\mathrm{Li} / \mathrm{Nb} / \mathrm{MgO}$ catalysts gave similar $\mathrm{C}_{2}$ yields at temperatures which were $30^{\circ} \mathrm{C}$ lower. Apparently, the promoting effect of the niobium was partly lost.

This deactivation of the catalysts was Investigated in more detail. In principle, several changes 


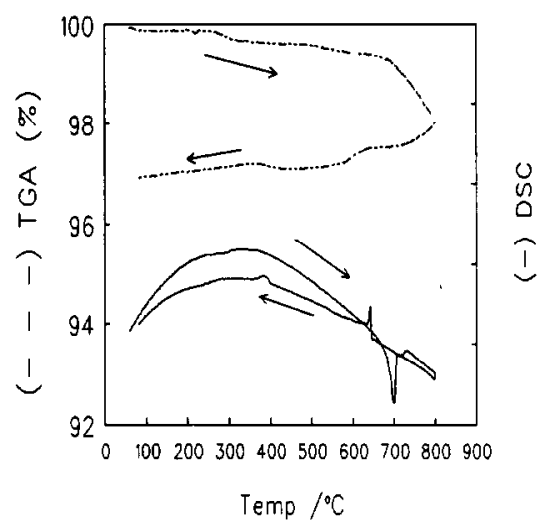

Figure 10 Thermal behaviour of $\mathrm{Li} / \mathrm{Nb} / \mathrm{MgO} \# 6$ in a stream of air, heating rate: $4{ }^{\circ} \mathrm{C} / \mathrm{min}$.

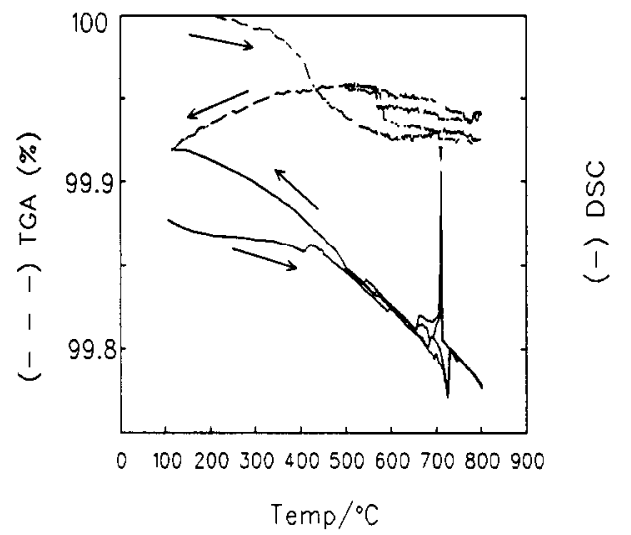

Figure 11 Thermal behaviour of $\mathrm{Li} / \mathrm{Nb} / \mathrm{MgO} \# 6$ in a stream of carbon dioxide. (heating rate $4{ }^{\circ} \mathrm{C} / \min$.)

can take place in the texture of catalyst, all of which can be responsible for the deactivation during the ageing process. These changes will now be discussed in turn.

i) Melting of lithium carbonate. As the catalyst has been used above the melting point of lithium carbonate during the first OCM test, the formation of a molten lithium carbonate phase will have taken place. The relationship between the melting point and the deactivation was investigated using catalyst $\mathrm{Li} / \mathrm{Nb} / \mathrm{MgO}(6)$ and the results are shown in Figure 9. The reactor temperature was first kept at $695^{\circ} \mathrm{C}$ for 15 hours, a temperature just below the melting point of the lithium carbonate phase. It was then increased to $720^{\circ} \mathrm{C}$, a temperature just above the melting point. Figure 9 shows that the $C_{2}$ yield increased from $7 \%$ to an initially higher value of $12 \%$. However, after this increase, the catalyst deactivated rapidly and the $\mathrm{C}_{2}$ yield decreased to only $2 \%$ after $30 \mathrm{hrs}$. These results indicate that the formation of the melt accelerates the deactivation of the $\mathrm{Li} / \mathrm{Nb} / \mathrm{MgO}$ catalyst.

ii) Loss of lithium. Loss of lithium may have taken place above the melting point; AAS experiments show that the used sample of $\mathrm{Li} / \mathrm{Nb} / \mathrm{MgO} \# 6$ indeed lost lithium (see Table 2). The XRD spectra also indicate that there has been a loss of lithium carbonate.

iii) Oxygen depletion. The catalyst has been used in a reducing atmosphere, once total oxygen conversion was achieved, this could have had a detrimental effect on any active niobate phase. A test equivalent to that shown in Figure 9 was carried out at $680^{\circ} \mathrm{C}$ but the oxygen dose in the feed stream was interrupted for 5 hours. The activity of the catalyst returned to the same level as before the oxygen interruption. This indicates that a reducing atmosphere (at $100 \%$ oxygen conversion) is not the reason for the loss of activity.

\section{Thermal Investigations in relation to Catalyst Performance}

According to Korf et al. [9], the loss of activity of the Li/MgO catalysts is mainly due to the loss of lithium, which evaporates in the form of lithium hydroxide. In order to get a better understanding of the evaporation of lithium, the weight change during heating was investigated. Figure 10 shows the melting behaviour of the sample $\mathrm{Li} / \mathrm{Nb} / \mathrm{MgO}(6)$ in a stream of air. while Figure 11 shows the melting behaviour of the same catalyst in a stream of carbon dioxide. In the latter case, the catalyst was heated and cooled in the temperature range from $500^{\circ} \mathrm{C}$ to $800^{\circ} \mathrm{C}$. The upper dotted line represents the TGA signal, while the lower line represents the DSC signal. When heated in air, the material showed an endothermic peak at $720^{\circ} \mathrm{C}$, presumably due to the melting of the lithium carbonate of the catalyst. The freezing point of the carbonate phase on cooling did not coincide with the melting point, presumably because of supercooling of the melt. When a higher heating rate $\left(e . g .10^{\circ} \mathrm{C} / \mathrm{min}\right.$ instead of $\left.4^{\circ} \mathrm{C} / \mathrm{min}\right)$ 


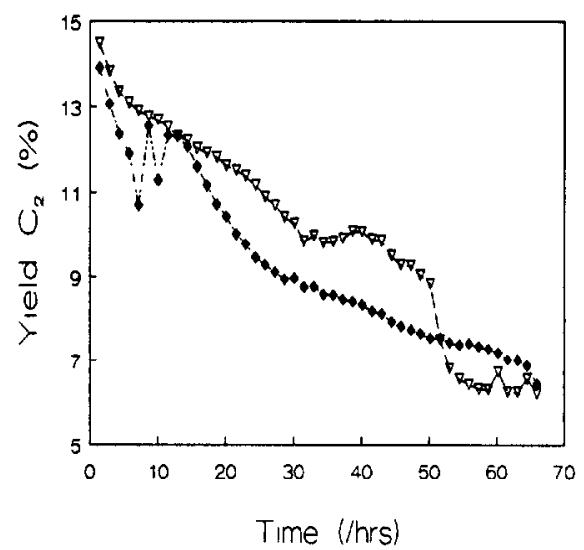

Figure 12 Aging, Cat; $L i / N b / M g O \quad 1$, Feed: $\mathrm{CH}_{4} / \mathrm{O}_{2}=5$, no $\mathrm{He}$, $\bullet$, no $\mathrm{CO}_{2}$ at $710{ }^{\circ} \mathrm{C}, \nabla, 2.5$ vol\% $\mathrm{CO}_{2}$ at $730^{\circ} \mathrm{C}$.

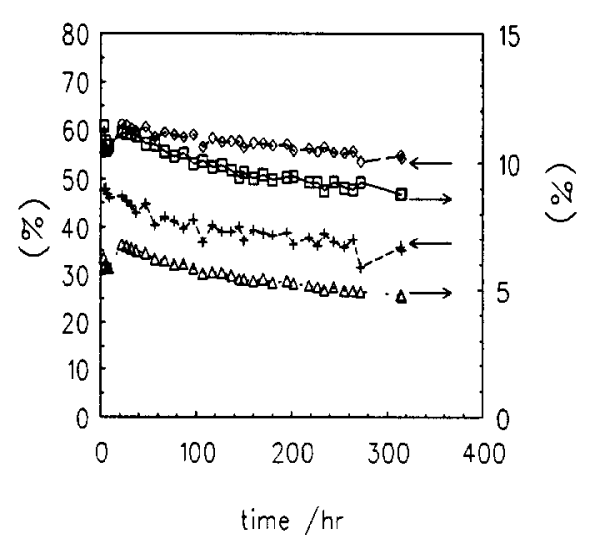

Figure 13 Ageing of $\mathrm{Li} / \mathrm{Nb} / \mathrm{MgO} \# 6,\left(\square, \mathrm{CH}_{4}\right.$ conversion; $+\mathrm{O}_{2}$ conversion; $\diamond$, selectivity to $\mathrm{C}_{2}$ prod.; $\Delta, \mathrm{C}_{2}$ yield, temp, $695{ }^{\circ} \mathrm{C}$ ).

was employed, a far larger difference was observed between the positions of the endothermic and of the exothermic peaks (not shown). We assume that the melting peak will coincide with the freezing peak when a very small heating rate is used. Similar conclusions concerning the melting and freezing behaviour were reached from experiments in a $\mathrm{CO}_{2}$ atmosphere (Figure 11). The TGA signal of Figure 9 shows that the catalyst lost weight rapidly after the melt has been formed. However, Figure 11 shows that the weight loss was negligible in a stream of carbon dioxide.

The weight loss represented in Figure 10 can be attributed to the decomposition of lithium carbonate. It has been reported [12] that lithium carbonate decomposes in the presence of water to form the hydroxide:

$$
\mathrm{Li}_{2} \mathrm{CO}_{3}+\mathrm{H}_{2} \mathrm{O}=2 \mathrm{LiOH}+\mathrm{CO}_{2}
$$

However, the results of Figure 11 show that the presence of $\mathrm{CO}_{2}$ in the reactant stream can shift the equilibrium to the left and hence can stabilize the $\mathrm{Li}_{2} \mathrm{CO}_{3}$ against decomposition [3]. Thus, the presence of carbon dioxide can possibly stabilise the catalyst system. Experiments dealing with this aspect are reported in the next section.

\section{Ageing experiments with and without addition of $\mathrm{CO}_{2}$ to the feed}

Figure 12 shows the behaviour of sample $\mathrm{Li} / \mathrm{Nb} / \mathrm{MgO} \# 1$ for the OCM reaction as a function of time, employing feeds with or without $\mathrm{CO}_{2}$. These experiments had to be carried out at two different temperatures, so that the results could be compared at similar $C_{2}$ Yields. Without addition of carbon dioxide to the feed, the catalyst showed an initial $\mathrm{C}_{2}$ yield of $14 \%$, which started to decrease almost instantaneously. The activity of the catalyst fluctuated after 10 hour due to a fluctuation of the reactor temperature. The yield dropped once more until after $60 \mathrm{hrs}$, it had decreased to $7 \%$. The addition of carbon dioxide had only a slight effect on the decline of the activity. We had shown that the addition of carbon dioxide to the feed prevents the loss of lithium, but in this case the addition of carbon dioxide to the feed had only a limited effect on the stability of the catalyst. It can be assumed that the water, produced during the OCM reaction, accelerated the decomposition of the lithium carbonate.

Figure 13 shows the activity of the catalyst $\mathrm{Li} / \mathrm{Nb} / \mathrm{MgO} \# 6$ for the $\mathrm{OCM}$ reaction and the selectivity to $\mathrm{C}_{2}$ products at $695^{\circ} \mathrm{C}$. During these experiments, an $\alpha \mathrm{Al}_{2} \mathrm{O}_{3}$ reactor was used and the feed consisted of $83 \mathrm{vol} \%$ methane and $17 \mathrm{vol} \%$ oxygen. The catalyst showed a far higher selectivity to carbon dioxide than the $\mathrm{Li} / \mathrm{MgO}$ and consequently a selectivity of 60 for $\mathrm{C}_{2}$ products was measured 
(versus $80 \%$ for the Li/MgO catalyst). Initially, a $\mathrm{C}_{2}$ yield of $7 \%$ was obtained. The figure shows that the activity of the catalyst decreased only slightly during ageing. After $320 \mathrm{hrs}$ the experiment was terminated although the catalyst was still active.

\section{CONCLUSIONS}

The results from the study of the effect of varying the preparation methods indicated that lithium should be added simultaneously with the niobium; this can be understood from the XRD results, which showed that the niobium of the active catalysts is present as lithium meta-niobate, the promoting phase. The method of catalyst preparation hardly influenced the performance of the catalysts, though one might expect that wet mixing results in a more homogeneous material than dry mixing. The high calcination temperatures used however permitted a relatively rapid solid state reaction to occur. It can therefore be assumed that the lithium carbonate still can react with the niobium oxide in the case of the dry mixing method.

An investigation of the catalyst texture showed that the surface areas of the $\mathrm{Li} / \mathrm{Nb} / \mathrm{MgO}$ catalysts were larger than the surface area of the $\mathrm{Li} / \mathrm{MgO}$ catalyst. XRD spectra showed the formation of two lithium niobate phases. After ageing the surface area decreased and the amount of the phases has decreased. It is therefore difficult to distinguish between the two factors.

The loss of activity of the $\mathrm{Li} / \mathrm{Nb} / \mathrm{MgO}$ catalyst for the $\mathrm{OCM}$ reaction after 60 hours ageing resemblances that of the $\mathrm{Li} / \mathrm{MgO}$ catalyst. $\mathrm{A} \mathrm{Li} / \mathrm{MgO}$ catalyst showed a $\mathrm{C}_{2}$ yield of $6 \%$ atter aging at $850^{\circ} \mathrm{C}$ [13]. In the case of the $\mathrm{Li} / \mathrm{Nb} / \mathrm{MgO}$ catalyst the $\mathrm{C}_{2}$ yield was $7 \%$, when operating at $695^{\circ} \mathrm{C}$. This indicates that the addition of niobium to the $\mathrm{Li} / \mathrm{MgO}$ catalyst permits the reduction of the reactor temperature. The ageing experiments show that the increased activity of the catalyst was lost and the $\mathrm{LiNbO}_{3}$ phase disappeared when the operating temperature is increased above the melting point of the $\mathrm{Li}_{2} \mathrm{CO}_{3}$ phase. The TGA-DSC results indicate that $\mathrm{Li}_{2} \mathrm{CO}_{3}$ decomposed rapidly above the melting point. This could indicate that when working above the melting point, lithium from the $\mathrm{LiNbO}_{3}$ phase is also lost and that this promotive phase consequently disappears.

\section{REFERENCES}

1. T. Ito and J.H. Lunsford, Nature, 314 (1985) 416.

2. J.H. Kolts and J.P. Guillory, E.P. no. 205.675, to Phillips Petroleum Co., appl 18 March 1986.

3. S.J. Korf, J.A. Roos, L.J. Veltman, J.G. van Ommen and J.R.H. Ross, Appl. Catal., 56 (1989) 119.

4. R.H.H. Smits, K. Seshan and J.R.H. Ross., J. Chem. Soc., Chem. Comm., 8 (1991) 558.

5. E.M. Thorsteinson, T.P. Wilson. F.G. Young and P.H. Kasai, J. Catal., 52 (1978) 116.

6. J.L. Brockwell and J.E. Kendall, Arabian J. Sci., Eng. 10 (1985) 351.

7. J.H. Kolts, U.S. 4.579.997., to Phillips Petroleum Co., appl. 1 April 1986.

8. D.J. McNamara, S.J. Korf, K. Seshan, J.G. van Ommen and J.R.H. Ross, Can. J. Chem. Eng., 69 (1991) 883

9. H.M. Swaan, A. Toebes, K. Seshan, J.G. van Ommen and J.R.H. Ross, Catal. Today., 13 (1992) 629.

10. S.J. Korf, J.A. Roos, N.A. de Bruijn, J.G. van Ommen and J.R.H. Ross, Appl Catal., 58 (1990) 131.

11. P.J. Jorgensen and R.W. Barlett, J. Phys. Chem. Solids, 30 (1969) 2639.

12. Gmelins Handbuch der Anorganische Chemie, $1^{\text {th }}$ Erg., $8^{\text {th }}$ edition, Li, syst. nr 20 , Verlag Chemie, Weinheim, 1960, p 497.

13. S.J. Korf, J.A. Roos, J A. Vreeman, J.W.H.C. Derksen, J.G. van Ommen and J.R.H. Ross, Catal. Today, 6 (1990) 417. 